\title{
Detecting Coal Self-heating by Condensation Aerosol Content in the Air
}

\author{
Vyacheslav Portola ${ }^{1, *}$, Alyona Bobrovnikova ${ }^{1}$, and Anastasia Shirokolobova $^{1}$ \\ ${ }^{1}$ T.F. Gorbachev Kuzbass State Technical University, 650000 Kemerovo, 28 Vesennya st., Russian \\ Federation
}

\begin{abstract}
The issues under consideration are spontaneous combustion of coal and the danger of endogenous fires for mining enterprises. The ways of detecting the hotbeds of spontaneous combustion which allow to increase the safety of mining works and to reduce economic damage from endogenous fires are analyzed. The temperature control is demonstrated to be ineffective due to thermal insulation properties of coal, and the gas analysis method - insufficient for detecting the initial stages of coal selfheating. It is proposed to detect the self-heating of coal by the condensation aerosol content formed at the cooling of the air heated in the source. The calculations of the condensation aerosol content in the air depending on the temperature of the coal self-heating spot are given. Dependences determining the temperature of coal self-heating spot, depending on the condensation aerosol content in the air passing through the coal have been obtained. Various sorbents for measuring condensation aerosol content in the air have been studied. The most effective sorbent of water vapor and condensation aerosol is macro-porous silica gel. A device detecting coal self-heating in mines, mine dumps, and coal storages has been developed. Tests in mine conditions proved the effectiveness of the method for detecting coal self-heating.
\end{abstract}

\section{Introduction}

Coal refers to substances capable of oxidizing by air oxygen at natural ambient temperatures. The process of oxygen sorption and the chemical reactions of coal combustible components oxidation are accompanied by the release of heat. Under favorable external conditions, the amount of heat released exceeds the loss of heat to the environment, which can lead to an increase of the coal temperature and to spontaneous combustion. The increase of coal crushing leads to the increase of active centers in the mine mass, which speeds up the sorption of oxygen resulting in the higher probability of spontaneous combustion.

Endogenous fires resulting from the development of spontaneous combustion cause enormous damages to coal enterprises. Underground fires can significantly pollute the atmosphere [1]. Endogenous fires are particularly dangerous for coal mines. The toxic gases releasing from the oxidizing coal are able to spread over long distances of mine openings, creating danger for people's health and life. Extinguishing of endogenous fires by isolation

\footnotetext{
*Corresponding author: portola2@yandex.ru
} 
method leads to the loss of coal mining equipment, mine openings, and coal reserves. The situation can get even worse due to methane emissions in mines since the hotbeds of spontaneous combustion may result in explosions of combustible gases and coal dust.

A number of scientific researches are devoted to the study of spontaneous combustion [29]. The results obtained allow predicting the probability of endogenous fires. Some technological processes, accompanied by an increase of the coal temperature, can speed up oxygen absorption, which drastically shortens the incubation period of spontaneous combustion [10]. Various methods of combating underground fires in mines have been developed, including the supply of inert gases [11]. Adding of frozen liquid particles to the gas raises the effectiveness of extinguishing under-ground fires [12].

There are many cases of coal spontaneous combustion in minerals storages, mine dumps. The air flows can move the released toxic gases to the places where people work and live. Intensive oxidation and ignition can significantly reduce the quality and cost of coal, leading to an increase in ash content and a decrease in its combustion heat. The high-temperature cavities in coal and mine dumps, formed in the hotbeds of spontaneous combustion are dangerous for people and equipment. There is a danger of explosion in case these cavities contact with water.

Methods of detecting the early stage of spontaneous combustion raise the effectiveness of combating the hotbeds of coal self-ignition and add to the safety of work in coal enterprises. The hotbeds of spontaneous combustion in mines are detected by measuring the temperature of the mine rock. The most common way of detecting the hotbeds of spontaneous combustion in coal mines is monitoring the composition of the mine atmosphere. In mines, the $\mathrm{CO}$ concentration which is the main indicator of the spontaneous combustion is measured with the help of stationary and portable instruments. The hotbeds of coal spontaneous combustion can also be indicated by the ratio of various gases in the mine atmosphere, as well as by the presence of radon [13].

However, practice shows that the gas analysis method is effective in detecting developed spots of spontaneous combustion, with a temperature of more than 150C, when the release of fire indicating gases rises sharply. Detecting the hotbeds of spontaneous combustion by measuring the temperature can be difficult due to thermal insulating properties of coal. The difficulty in identifying the initial stages of spontaneous combustion by gas analysis method is that the fire-indicating gases in the mined area and on mining face can release due to various natural factors of internal and external origin, without the rise of the coal temperature. Thus, the emission of indicator gases during the breaking of coal, and also during lowtemperature oxidation is sharply intensified. The $\mathrm{CO}$ concentration in the atmosphere of the mined-out space is often excessive, which makes the timely detection of spontaneous combustion more complicated. Thus, at the Kolmogorovskaya mine, the $\mathrm{CO}$ concentration in the air samples from the mined-out space of the active lava reached $0.01 \%$, which led to stops of coal mining and to the requirements for isolation of the site. However, after some time, the concentration of the indicator gas returned to normal. Eventually, the lava was worked out and isolated without signs of an endogenous fire.

A method of fixing the increase in the moisture content of air passing through coal allows increasing the efficiency of detecting the early stage of the self-heating process. The moisture content of air, equal to the ratio of the vapor mass in moist air to the mass of dry air, depends on two parameters - the temperature and the relative humidity of the gas. The increase in the moisture content of air passing through the coal mass with the hotbed of self-heating is mainly the result of the evaporation of moisture from the heated coal. The moisture content of air is calculated by the formula

$$
d=0,622 \frac{P_{p} \varphi}{P_{0}-P_{p} \varphi},
$$


where $\mathrm{P}_{\mathrm{p}}$ is the saturated vapor pressure; $\mathrm{P}_{0}$ is the barometric air pressure; $\varphi$ - relative air humidity.

The analysis of the above formula shows that an increase in moisture content occurs with the temperature rise of the moist air, leading to the pressure rise of saturated vapor and its relative humidity. Taking into account two air parameters allows for better reliability of information about self-heating processes.

\section{Materials and Methods}

The existing method often does not allow detecting self-heating in mines, since in practice the moisture content of air does not always rise after passing through heated coal, even with the intensive evaporation of moisture. This happens when the air entering the coal mass already has a relative humidity close to $100 \%$. The use of water for technological purposes and a large natural water inflow in mines can be the reason for this state. In the warm season, the air flowing into the mine can have high vapor content and after cooling in the mine works to the temperature of the mine rocks its relative humidity often reaches $100 \%$ without additional evaporation. Taking into account that the relative humidity of the air passing through the mined-out space cannot exceed $100 \%$, this parameter in such cases cannot give information about self-heating processes.

The method of detecting the early stage spontaneous combustion can be expanded in scope and effectiveness. A necessary thing to consider is that beside the vapor content, other parameters in the air passing through the heated coal mass change too. Thus, in the beginning, the incoming air heats up in the hotbed of self-heating, its relative humidity lowers stimulating moisture evaporation from the coal. As a result of evaporation, the moisture content of the air rises. After passing the hotbed of self-heating, the heated air begins to cool down to the natural temperature of the coal due to the developed surface of the mine rock mass. This process is accompanied by the raise of relative air humidity to $100 \%$, followed by condensation of excess moisture.

The resulting liquid phase is suspended in the form of a fine aerosol. As a result, the outgoing air flow, as well as the incoming air, will have a relative humidity close to $100 \%$ and the natural temperature of the mine rock. In this case, the moisture content of the air after passing through the heated coal will not change, but the liquid phase will appear in the form of an aerosol. When high-humidity coal in mines begins to self-heat, the formation of fog can be observed. However, in most cases, such aerosols are not easily detected visually, which reduces the efficiency of physio-logical methods of detecting self-heating.

The amount of condensation aerosol in the air that passed the heated coal mass was rated by calculation method. Various substances capable of absorbing condensation aerosols from the mine atmosphere were tested in the lab. The amount of absorbed vapor and condensation aerosol was defined by weighing. The conducted experiments allowed designing the equipment for the detection of coal self-heating, which was tested in mine conditions.

\section{Results and Discussion}

Given the phenomenon of vapor condensation at air cooling, it is possible to increase the efficiency of the known method of detecting the self-heating by taking into account such parameter as the amount of air moisture in the form of fine aerosol. The following expression can be given as a criterion for detecting the early stage of self-heating, which takes into account the total amount of air moisture both in the form of vapor and liquid forming the aerosol 


$$
K=0,622 \frac{P_{p} \varphi}{P_{0}-P_{p} \varphi}+M,
$$

where $\mathrm{M}$ is the amount of aerosol in the air formed by condensation of vapor, $\mathrm{kg} / \mathrm{kg}$.

The pressure of saturated water vapor in the air depends on the temperature and can be defined by the formula

$$
P_{p}=P_{1} e^{-L /(R T)}
$$

where $\mathrm{P}_{1}$-constant; L-specific heat of evaporation; R-universal gas constant; $\mathrm{T}$ thermodynamic temperature.

The amount of aerosol in the air after passing through the hotbed of self-heating can be defined by the formula

$$
M=0,622\left(\frac{\varphi_{0} P_{1} e^{-L \mid R T_{0}}}{P_{0}-\varphi_{0} P_{1} e^{-L \mid R T_{0}}}-\frac{\varphi P_{1} e^{-L \mid R T}}{P_{0}-\varphi P_{1} e^{-L \mid R T}}\right),
$$

where $\mathrm{T}_{0}$ is the temperature of the hotbed of self-heating; $\mathrm{T}$ is the natural temperature of the coal; $\varphi_{0}$ is the relative humidity of the air in the hotbed of self-heating; $\varphi$ is the relative humidity of the air at the natural temperature of the coal.

The calculations show that the amount of liquid phase in the air that has passed through the heated coal can significantly exceed the amount of vapor in it. Fig. 1 shows how the temperature of the self-heating spot influences the ratio of liquid phase and vapor in the air after its cooling. In this case, at heat, the air was saturated with water vapor to a relative humidity of $100 \%$, and then cooled to a temperature of $15^{\circ} \mathrm{C}$. The provided data displays that after passing through the coal mass with a temperature of more than $60^{\circ} \mathrm{C}$, the amount of liquid aerosol formed in the cooled air can be tens of times greater than the amount of the remaining vapor. Therefore, the detection of coal self-heating by condensation aerosol in the air can significantly improve the accuracy of the detecting method and expand the scope of its application.

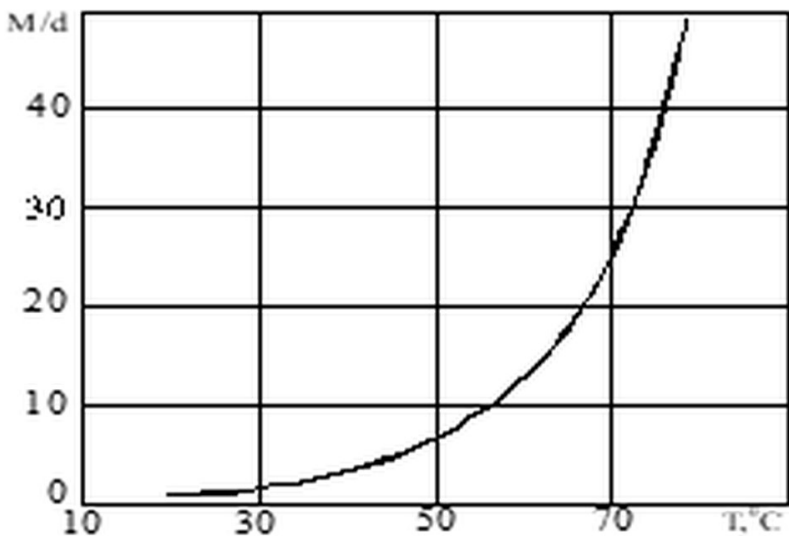

Fig. 1. Effect of the temperature of self-heating hotbed on the ratio of the liquid phase (M) and vapor (d) in the air after its cooling.

The measurements in mines showed that the aerosol can also appear in existing mine works due to natural processes. Thus, in a warm season, the incoming air in a mine is warm and with higher humidity. Moving along the mine works, it cools down, and the moisture begins condensing. Therefore, the vapor content and the amount of liquid phase in the air 
should be measured not only in the outgoing, but also in the incoming flow entering the mined-out space. The amount of the liquid phase in the air must be mandatory defined in cases when its relative humidity is $100 \%$.

The liquid suspended in the air can be measured with the help of different sorbents, for ex-ample, silica gel. In this case, the mine air is passed through containers with a drying substance, and then they are weighed. The rise of K-criterion in the airflow after passing through the mined-out space indicates self-heating. The coal self-heating appears under the following conditions

$$
\mathrm{K}_{\text {out }}-\mathrm{K}_{\text {in }}>0 \text { or } \mathrm{K}_{\text {out }} / \mathrm{K}_{\text {in }}>1 \text {, }
$$

where $\mathrm{K}$ out is the total amount of vapor and liquid aerosol in the air going out of the mined-out space; $\mathrm{K}$ in is the total amount of vapor and liquid aerosol in the ambient air.

This new criterion also allows to rate the temperature of the self-heating hotbed by the amount of condensed liquid. Assuming that all the amount of liquid condensed at the control point was in the form of vapor at a humidity of $100 \%$ and using formulas (1), (2) and (3), we obtain a formula for determining the temperature of the heated coal

$$
T=\frac{L}{R \ln \left[\frac{P_{1}\left(K_{i}+0,622\right)}{K_{i} P_{0}}\right]},
$$

where $\mathrm{Ki}$ is the total amount of vapor and liquid aerosols in air outgoing of the mined-out space.

A special device with a pump and a container with sorbent was developed for detecting coal self-heating in mines by the aerosol formed. The work performance of the developed device was tested in lab conditions. Silica gel and activated carbon were used as a sorbent. The aerosol water cloud was created using an ultrasonic air humidifier.

The tests have shown macro-porous silica gel to be the most effective sorbent for absorbing vapor and liquid aerosol (Table 1).

Table 1. Change of silica gel sample mass.

\begin{tabular}{|c|c|c|c|}
\hline № & $\begin{array}{c}\text { Initial mass of the } \\
\text { sample, } \mathrm{g}\end{array}$ & $\begin{array}{c}\text { Sample mass after air } \\
\text { supply, } \mathrm{g}\end{array}$ & $\begin{array}{c}\text { Mass of absorbed vapor and } \\
\text { aerosol, } \mathrm{g}\end{array}$ \\
\hline 1 & 13.35 & 13.60 & 0.25 \\
\hline 2 & 13.50 & 13.76 & 0.26 \\
\hline 3 & 13.10 & 13.36 & 0.26 \\
\hline 4 & 13.30 & 13.56 & 0.26 \\
\hline 5 & 13.70 & 13.97 & 0.27 \\
\hline 6 & 13.50 & 13.75 & 0.25 \\
\hline 7 & 13.52 & 13.79 & 0.27 \\
\hline
\end{tabular}

The developed method and device for detecting the early stages of spontaneous combustion were tested in lab and in mine conditions. The tests have shown that the device has decent accuracy to determine the mass of the condensation aerosol in the air, and can be used to identify coal self-heating. The tests have also shown that this method and the device allow estimating the temperature of the self-heating hotbeds. The method is especially effective in cases when unexplained fluctuations in the concentration of carbon monoxide occur in the mine atmosphere.

The developed method can also be used to detect self-heating processes in mine dumps and coal storages. The hotbeds of spontaneous combustion deep in the coal mass can be detected visually by the signs of vapor emission. However, such signs usually occur after atmospheric precipitation and over the hotbeds that have a sufficiently high temperature. In 
other cases, a laborious method of measuring the temperatures in the wells and bores pierced in the coal mass is used. Pumping the air released from the coal mass through a device measuring the content of water vapor and water aerosol (Fig. 2) can significantly simplify the task of detecting the spots of self-heating.

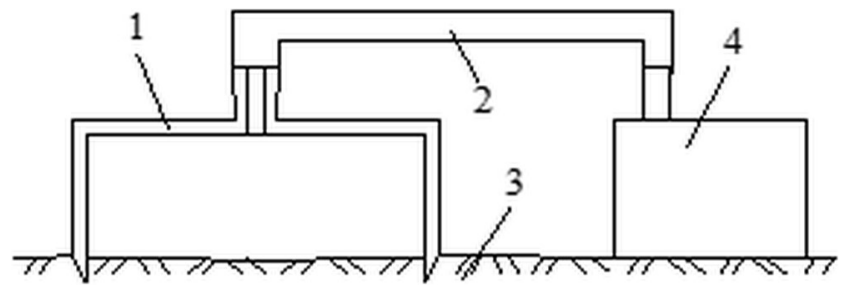

Fig. 2. The scheme of the device measuring the moisture released on the surface: 1 - container; 2 nozzle; 3 - surface; 4 - sorbent pump.

Containers 1 are installed for detecting the hotbeds of self-heating on the surface of mine dumps or coal storages. The gas released from the surface is pumped through the sorbent. Then the total content of water vapor and water aerosol in the gas is determined. A similar air sampling is made from the surrounding atmosphere. The fact of self-heating is determined by the formulas (3), the coal temperature - by the expression (5). Application of the developed method also allows determining the location of self-heating hotbeds in coal mass or carboncontaining rocks.

\section{Conclusions}

The conducted research allows drawing the following conclusions.

1. The existing gas analysis methods do not detect the early stage of spontaneous coal com-bustion.

2. Detecting the coal self-heating by vapor content of the air is not effective at high air hu-midity typical of the mine atmosphere.

3. Measuring the total content of water vapor and particles of condensed moisture in the air allows detecting the beginning of coal self-heating at any air humidity.

4. Measuring the total moisture content of air allows determining the temperature of the self-heating hotbed.

5. Macro-porous silica gel is the most effective sorbent for detecting self-heating by the con-tent of condensation aerosol in the air.

6. The developed method can be used for detecting the spots of self-heating in mine dumps and coal storages.

\section{References}

1. J.W. Weier, Fire in Hole, Sciences, 37:6, 12 (1997)

2. Q. Lin, S. Wang, S. Song, Y. Liang, T Ren, Fuel processing Technology, 159, 38 (2017)

3. S.C. Banerjee, Spontaneous Fire Risk Estimation and its Prevention. Prevention and combating Mine Fires (IMSA, Bombay, 2000)

4. M.N. Tarafadar, D. Guha, Application of Wet Oxidation Processes for the Assessment of the spontaneous heating of Coal. Fuel, 68, 315 (1989)

5. D.S. Nimaje, D.P. Tripathy, The Indian Mining \& Engineering Journal, 10, 3 (2010)

6. J. Deng, J.-Y. Zhao, Y.-N. Zhang, C.-R. Wang, A.-C. Huang, C.-M. Shu, Journal of Thermal Analysis \& amp, 127:1, 439 (2017) 
7. L. Zhang, B. Qin, Fire and materials, 40:2, 246 (2016)

8. A. Rosema, Y. Guan, H. Veld, Article in Fuel, 80:1, 7 (2001)

9. Q.S. Wang, D. Guo, J.H. Sun, Energy and Fuels, 23:10, 4871 (2009)

10. V.A. Portola, E.S. Torosyan, A.S., Applied Mechanics and materials: Scientific Journal, 770, 690 (2015)

11. K. Takeshi, I. Takehiro, Mining Sci. and Technol, 8:2, 145 (1989)

12. V. Portola, N. Galsanov, Taishan Academic Forum - Project on Vine Disaster Prevention and Control, 1, 356 (2014)

13. V. A. Portola, E. S. Torosyan, V. K. Antufeyev, IOP Conference Series: Materials Science and engineering, 127, 02013 (2016) 